\title{
The impact of two different inspiratory to expiratory ratios $(1: 1$ and 1:2) on respiratory mechanics and oxygenation during volume-controlled ventilation in robot-assisted laparoscopic radical prostatectomy: a randomized controlled trial L'impact de deux ratios inspiratoire à expiratoire différents (1:1 et 1:2) sur la mécanique respiratoire et l'oxygénation pendant la ventilation en volume contrôlé en cas de prostatectomie radicale laparoscopique sous assistance robotisée: une étude randomisée contrôlée
}

\author{
Min-Soo Kim, MD • Na Young Kim, MD $\cdot$ Ki-Young Lee, MD, PhD • \\ Young Deuk Choi, MD, PhD · Jung Hwa Hong, MS $\cdot$ Sun-Joon Bai, MD, PhD
}

Received: 1 December 2014/Accepted: 1 April 2015/Published online: 14 April 2015

(C) Canadian Anesthesiologists' Society 2015

\begin{abstract}
Background Volume-controlled ventilation with a prolonged inspiratory to expiratory ratio (I:E ratio) has been used to optimize gas exchange and respiratory mechanics in various surgical settings. We hypothesized that, when compared with an I:E ratio of 1:2, a prolonged I:E ratio of 1:1 would improve respiratory mechanics without reducing cardiac output (CO) during
\end{abstract}

\footnotetext{
Author contributions $\quad$ Min-Soo Kim and Na Young Kim contributed equally to this work.Min-Soo Kim, $\mathrm{Na}$ Young Kim, KiYoung Lee, and Sun-Joon Bai contributed to the study design and preparation of the manuscript. Min-Soo Kim, Na Young Kim, and KiYoung Lee contributed to data acquisition. Min-Soo Kim, Na Young Kim, and Sun-Joon Bai contributed to the data analysis. Young Deuk Choi contributed to patient recruitment and data collection. Jung Hwa Hong contributed to statistical analysis.
}

M.-S. Kim, MD · N. Y. Kim, MD · K.-Y. Lee, MD, PhD S.-J. Bai, MD, PhD (ه)

Department of Anesthesiology and Pain Medicine, Anesthesia and Pain Research Institute, Yonsei University College of Medicine, 50-1 Yonsei-ro, Seodaemun-gu, Seoul 120-752, Korea e-mail: sjbai1@yuhs.ac

Y. D. Choi, MD, PhD

Department of Urology and Urological Science Institute, Yonsei University College of Medicine, Seoul, Korea

J. H. Hong, MS

Biostatistics Collaboration Units, Department of Research

Affairs, Yonsei University College of Medicine, Seoul, Korea pneumoperitoneum and steep Trendelenburg positioning, both of which can impair respiratory function in robotassisted laparoscopic radical prostatectomy. Furthermore, we evaluated its effect on oxygenation during robotassisted laparoscopic radical prostatectomy.

Methods Eighty patients undergoing robot-assisted laparoscopic radical prostatectomy were randomly allocated to receive an I:E ratio of either 1:1 (group 1:1) or 1:2 (group 1:2). The primary endpoint, peak airway pressure (Ppeak), as well as hemodynamic data, including cardiac output ( $\mathrm{CO}$ ) and arterial oxygen tension $\left(\mathrm{PaO}_{2}\right)$, were compared between groups at four time points: ten minutes after anesthesia induction (T1), 30 and 60 min after pneumoperitoneum with steep Trendelenburg positioning (T2 and T3), and ten minutes after supine positioning (T4). Overall comparisons were made between groups using linear mixed model analysis with post hoc testing of individual time points adjusted using a Bonferroni correction.

Results Linear mixed model analysis showed a significant overall difference in Ppeak between the two groups $(P<0.001)$. Post hoc analysis showed a significantly lower mean (SD) Ppeak in group 1:1 than in group $1: 2$ at $\mathrm{T2}$ [28.4 (4.0) $\mathrm{cm} \mathrm{H}_{2} \mathrm{O}$ vs 32.8 (5.2) $\mathrm{cm} \mathrm{H}_{2} \mathrm{O}$, respectively; mean difference, $4.3 \mathrm{~cm} \mathrm{H}_{2} \mathrm{O} ; 95 \%$ confidence interval (CI), 2.3 to 6.4; $P<0.001]$ and T3 [27.8 (3.9) $\mathrm{cm} \mathrm{H}_{2} \mathrm{O}$ vs 32.6 (5.0) $\mathrm{cm} \mathrm{H}_{2} \mathrm{O}$, respectively; mean difference, $4.7 \mathrm{~cm} \mathrm{H}_{2} \mathrm{O} ; 95 \% \mathrm{CI}, 2.7$ to 6.7 ; 
$P<0.001]$. The CO assessed over these time points was comparable in both groups $(P=0.784)$. In addition, there were no significant differences in $\mathrm{PaO}_{2}$ between the two groups $(P=0.521)$.

Conclusions Compared with an I:E ratio of 1:2, a ratio of 1:1 lowered Ppeak without reducing $\mathrm{CO}$ during pneumoperitoneum and steep Trendelenburg positioning. Nevertheless, our results did not support its use solely for improving oxygenation. This trial was registered at http:// clinicaltrials.gov/ (NCT01892449).

\section{Résumé}

Contexte La ventilation en volume contrôlé avec un ratio inspiratoire à expiratoire prolongé (ratio I:E) a été utilisée pour optimiser l'échange gazeux et la mécanique respiratoire dans divers contextes chirurgicaux. Nous avons émis l'hypothèse que, comparativement à un ratio I:E de 1:2, un ratio I:E prolongé de 1:1 améliorerait la mécanique respiratoire sans réduire le débit cardiaque (DC) pendant un pneumopéritoine en position de Trendelenburg très inclinée, deux facteurs pouvant entraver la fonction respiratoire lors d'une prostatectomie radicale laparoscopique sous assistance robotisée. Nous avons également évalué l'effet de cette mesure sur l'oxygénation pendant une prostatectomie radicale laparoscopique sous assistance robotisée.

Méthode Quatre-vingts patients subissant une prostatectomie radicale laparoscopique sous assistance robotisée ont été aléatoirement répartis à recevoir un ratio I:E de 1:1 (groupe 1:1) ou un ratio I:E de 1:2 (groupe 1:2). Le critère d'évaluation principal, soit la pression maximale des voies aériennes (Ppic), ainsi que les données hémodynamiques, notamment le débit cardiaque $(D C)$ et la pression artérielle en oxygène $\left(\mathrm{PaO}_{2}\right)$, ont été comparés entre les groupes à quatre points dans le temps: dix minutes après l'induction de l'anesthésie (T1), 30 et $60 \mathrm{~min}$ après le pneumopéritoine en position de Trendelenburg très inclinée (T2 et T3), et dix minutes après le positionnement couché sur le dos (T4). Les comparaisons globales entre les groupes ont été réalisées à l'aide d'une analyse par modèle linéaire mixte avec des tests post hoc de chacun des points dans le temps ajustés à l'aide d'une correction de Bonferroni.

Résultats L'analyse par modèle linéaire mixte a montré une différence globale significative de la Ppic entre les deux groupes $(P<0,001)$. L'analyse post hoc a montré une Ppic moyenne (ÉT) significativement plus basse dans le groupe 1:1 par rapport au groupe 1:2 à T2 [28,4 $(4,0) \mathrm{cm}$ $\mathrm{H}_{2} \mathrm{O}$ vs $32,8(5,2) \mathrm{cm}_{2} \mathrm{O}$, respectivement; différence moyenne, 4,3 $\mathrm{cm} \mathrm{H}_{2} \mathrm{O}$; intervalle de confiance (IC) $95 \%$, $2,3$ à 6,4; $\mathrm{P}<0,001]$ et à T3 $\left[27,8(3,9) \mathrm{cm} \mathrm{H}_{2} \mathrm{O}\right.$ vs 32,6 $(5,0) \mathrm{cm} \mathrm{H}_{2} \mathrm{O}$, respectivement; différence moyenne, $4,7 \mathrm{~cm}$ $\mathrm{H}_{2} \mathrm{O}$; IC $95 \%, 2,7$ à 6,7; $\left.\mathrm{P}<0,001\right]$. Le DC évalué au cours de ces points dans le temps était comparable dans les deux groupes $(P=0,784)$. En outre, aucune différence significative n'a été observée en matière de $\mathrm{PaO}_{2}$ entre les deux groupes $(P=0,521)$.

Conclusion Par rapport à un ratio I:E de 1:2, un ratio de 1:1 a réduit la Ppic sans réduire le DC pendant le pneumopéritoine en position de Trendelenburg très inclinée. Toutefois, nos résultats n'appuient pas son utilisation uniquement pour améliorer l'oxygénation. Cette étude a été enregistrée au http://clinicaltrials.gov (NCT01892449).

Carbon dioxide $\left(\mathrm{CO}_{2}\right)$ pneumoperitoneum and steep Trendelenburg positioning are used in combination to optimize the surgical view during robotic-assisted laparoscopic operations. Nevertheless, they can be associated with adverse physiologic effects on various organs, including those of the respiratory system..$^{1-3}$ For example, the increased intra-abdominal pressure can lead to reductions in functional residual capacity and lung compliance. The resultant atelectasis impairs oxygenation, and the consequent higher airway pressure increases the risk of barotrauma. ${ }^{1,4}$

Ventilation with a more prolonged inspiratory to expiratory ratio (I:E ratio) has become an alternative strategy for improving gas exchange and respiratory mechanics. This strategy is used not only in critical patients with acute respiratory distress syndrome but also in surgical patients with reduced lung compliance due to surgical factors during general anesthesia. ${ }^{5-8}$ On the contrary, this method could lead to a decrease in cardiac output (CO) due to increases in intrathoracic pressure, which reduces venous return. ${ }^{7}$ Therefore, it should be applied cautiously, particularly in the elderly who may have significant inter-individual variability and limited physiologic reserve. ${ }^{7,9}$ Robot-assisted laparoscopic radical prostatectomy is a commonly performed robotic surgery using pneumoperitoneum with steep Trendelenburg positioning. ${ }^{4}$ Respiratory mechanics might be improved when using a prolonged I:E ratio during robot-assisted laparoscopic radical prostatectomy, but there is also the potential to reduce $\mathrm{CO}$. Nevertheless, definitive information about the appropriate I:E ratio in robot-assisted laparoscopic radical prostatectomy is currently lacking.

This study aimed to investigate the effects of a prolonged I:E ratio (i.e., 1:1) compared with the conventional I:E ratio of $1: 2$ on respiratory mechanics and hemodynamics during pneumoperitoneum with steep Trendelenburg positioning in a robot-assisted laparoscopic radical prostatectomy. We hypothesized that, compared with an I:E ratio of 1:2, a ratio of 1:1 attenuates increases in peak airway pressure (Ppeak) without hemodynamic 
instability in robot-assisted laparoscopic radical prostatectomy. Furthermore, the effect on oxygenation was compared between the two groups.

\section{Methods}

This prospective randomized double-blind parallel-group single-site trial was approved by the Institutional Review Board of Severance Hospital, Yonsei University Health System, Seoul, Korea on June 26, 2013 (ref: 4-2013-0287). This study was conducted from July 2013 to February 2014 in Severance Hospital in Seoul, Korea.

After written informed consent was obtained from all patients, 80 adult male patients were enrolled in the study. Enrolment criteria included American Society of Anesthesiologists physical status class I-II and scheduled for an elective robot-assisted laparoscopic radical prostatectomy using the da Vinci ${ }^{\mathrm{TM}}$ Surgical System (Intuitive Surgical, Inc., Mountain View, CA, USA). Patients with an abnormal airway anatomy, reactive airway diseases, chronic respiratory diseases, history of coronary artery disease, heart failure, and obesity (body mass index $[\mathrm{BMI}]>30 \mathrm{~kg} \cdot \mathrm{m}^{-2}$ ) were excluded.

Standard monitoring techniques, ${ }^{10}$ including electrocardiography, pulse oximetry, and noninvasive arterial blood pressure measurement, were applied upon arrival at the operating room. Before anesthesia induction, $\mathrm{CO}$ monitoring using the NICOM device (Cheetah Medical, Portland, OR, USA) was initiated with placement of four dual-electrode stickers on the patient's upper back and lower flank in accordance with the manufacturer's instructions. Anesthesia was induced with intravenous propofol $1.5 \mathrm{mg} \cdot \mathrm{kg}^{-1}$ and was maintained with an end-tidal concentration of $5-6 \%$ desflurane in $100 \%$ oxygen. In order to facilitate orotracheal intubation, rocuronium $0.6 \mathrm{mg} \cdot \mathrm{kg}^{-1}$ was administered intravenously with an infusion of remifentanil at $0.1-0.2 \mu \mathrm{g} \cdot \mathrm{kg}^{-1} \cdot \mathrm{min}^{-1}$. After tracheal intubation, volume-controlled ventilation was initiated with an inspiratory pause of $10 \%$, an I:E ratio of 1:2, no positive end-expiratory pressure, and a tidal volume of $8 \mathrm{~mL}$ per ideal body weight $(\mathrm{kg})$. A respiratory rate was adjusted in order to maintain a mean (SD) endtidal carbon dioxide $\left(\mathrm{EtCO}_{2}\right)$ of 38 (2) $\mathrm{mmHg}$ during surgery. Anesthesia was maintained with remifentanil 0.05 $0.2 \mu \mathrm{g} \cdot \mathrm{kg}^{-1} \cdot \mathrm{min}^{-1}$ and an end-tidal concentration of $5-7 \%$ desflurane in $50 \%$ oxygen/air. The bispectral index score was monitored continuously using the A-2000 ${ }^{\mathrm{TM}} \mathrm{BIS}^{\circledR}$ Monitoring System (Aspect Medical System Inc., Newton, MA, USA) in order to maintain an adequate anesthetic depth and was targeted at a range of 40-60 during surgery. Radial artery cannulation was conducted for monitoring continuous arterial blood pressure and blood sampling.
During surgery, the mean arterial pressure and heart rate were maintained within $20 \%$ of baseline by titration of anesthetics, fluid replacement, and intravenous administration of vasoactive drugs (ephedrine or phenylephrine) at the discretion of the attending anesthesiologists. A Bair Hugger ${ }^{\mathrm{TM}}$ forced-air warming system (Augustine-Medical, Eden Prairie, MN, USA) was used to maintain body temperature at $36.0-37.0^{\circ} \mathrm{C}$ during the intraoperative period.

The enrolled patients were randomly allocated according to a predetermined allocation sequence to receive an $\mathrm{I}: \mathrm{E}$ ratio of either $1: 1$ (group 1:1) or $1: 2$ (group 1:2) during $\mathrm{CO}_{2}$ pneumoperitoneum with steep Trendelenburg positioning. The allocation sequence with no blocking was generated in an Internet website (http:// www.random.org/) and was concealed in a sealed envelope. Patient enrolment and randomization were performed by a researcher who was not involved in anesthesia care or outcome analysis. Independent experienced anesthesiologists provided the anesthesia care in the same manner. The attending anesthesiologists and outcome assessors were aware of the allocated I:E ratio, but the patients, urologists, and data analysts were blinded to group allocation.

One of two urologists with experience in robot-assisted laparoscopic radical prostatectomy performed each surgery. After induction of anesthesia, $\mathrm{CO}_{2}$ pneumoperitoneum was established with an intraabdominal pressure of $15 \mathrm{mmHg}$ in the supine position, and then a $29^{\circ}$ Trendelenburg position was achieved accurately by using the operating bed controller which showed the tilting angle in numbers. Immediately after $\mathrm{CO}_{2}$ pneumoperitoneum with steep Trendelenburg positioning, the $\mathrm{I}: \mathrm{E}$ ratio was adjusted according to the allocated group without changing the other ventilator parameters. In group 1:1, the I:E ratio was changed from 1:1 to $1: 2$ immediately after $\mathrm{CO}_{2}$ desufflation and supine positioning.

Respiratory, hemodynamic, and arterial blood gas data were assessed and recorded at four time points: ten minutes after anesthesia induction in the supine position (T1), $30 \mathrm{~min}$ after Trendelenburg positioning with $\mathrm{CO}_{2}$ pneumoperitoneum (T2), $60 \mathrm{~min}$ after Trendelenburg positioning with $\mathrm{CO}_{2}$ pneumoperitoneum (T3), and ten minutes after supine positioning without $\mathrm{CO}_{2}$ pneumoperitoneum (T4). Respiratory data consisted of Ppeak, plateau airway pressure (Pplat), mean airway pressure (Pmean), static compliance, $\mathrm{EtCO}_{2}$, respiratory rate, and minute volume, which were measured and described by the Primus ${ }^{\circledR}$ anesthesia workstation (Dräger, Lübeck, Germany). Hemodynamic data included blood pressure, heart rate, $\mathrm{CO}$, cardiac output index, stroke volume, stroke volume index, and stroke volume variation. 
Arterial $\mathrm{pH}$, arterial oxygen tension $\left(\mathrm{PaO}_{2}\right)$, arterial carbon dioxide tension $\left(\mathrm{PaCO}_{2}\right)$, and lactate level were obtained from arterial blood gas analysis.

In addition to these variables, we also investigated the duration of anesthesia, the period of surgery and pneumoperitoneum, fluid and blood administration, urine output, blood loss, the amount of vasopressor administered, duration of stay in the postanesthesia care unit, and duration of postoperative hospital stay. Hemodynamic instability was treated with intravenous ephedrine $(\mathrm{mg})$ and/or phenylephrine $(\mu \mathrm{g})$ in both groups. Our study protocol was designed to withdraw the patient if arterial oxygen saturation (as measured by pulse oximetry) decreased to $<95 \%$ or if the Ppeak increased to $>40 \mathrm{~cm}$ $\mathrm{H}_{2} \mathrm{O}$ during surgery. ${ }^{11}$

\section{Statistical analysis}

Statistical analysis was conducted using SAS ${ }^{\circledR}$ version 9.2 (SAS Institute Inc., Cary, NC, USA). All data are presented as mean standard deviation (SD) or number of patients (\%). The primary outcome was Ppeak during $\mathrm{CO}_{2}$ pneumoperitoneum with steep Trendelenburg positioning. Secondary outcomes were $\mathrm{PaO}_{2}$ and $\mathrm{CO}$. Due to a lack of previous studies comparing different I:E ratios of 1:1 and 1:2 in robot-assisted laparoscopic radical prostatectomy, the sample size was calculated on the basis of a previous study comparing volume-controlled and pressurecontrolled ventilation (PCV) in robot-assisted laparoscopic radical prostatectomy. ${ }^{11}$ We calculated that 31 patients per group would be required to detect a difference of $3 \mathrm{~cm} \mathrm{H}_{2} \mathrm{O}$ (i.e., approximately $10 \%$ change) with an alpha level of 0.05 and a power of $80 \%$. In order to compensate for patient dropout and to increase the study power, 40 patients per group were recruited.

Data comparisons between the two groups were performed using an independent two-sample Student's $t$ test and the Chi square or Fisher's exact test depending on the characteristics of the data. A linear mixed model using an unstructured covariance pattern for repeated measures was utilized to compare continuous variables, including the primary and secondary outcomes, which were investigated at each time point. If overall differences were observed among values at each time point, post hoc analysis for multiple comparisons was conducted using the Bonferroni correction. All statistical tests were two-tailed, and all reported $P$ values are two sided.

\section{Results}

Eighty-two patients were initially assessed for eligibility. Two patients were excluded from the study; one patient did not give consent and one other was obese (BMI $>30 \mathrm{~kg} \cdot \mathrm{m}^{-2}$ ). Among the 80 patients who were enrolled and randomized, one patient in group 1:1, who underwent nephrectomy combined with robot-assisted laparoscopic radical prostatectomy, was further excluded from the analysis, which left 79 patients available for analysis (Fig. 1). The
Fig. 1 Consort flow diagram of our study

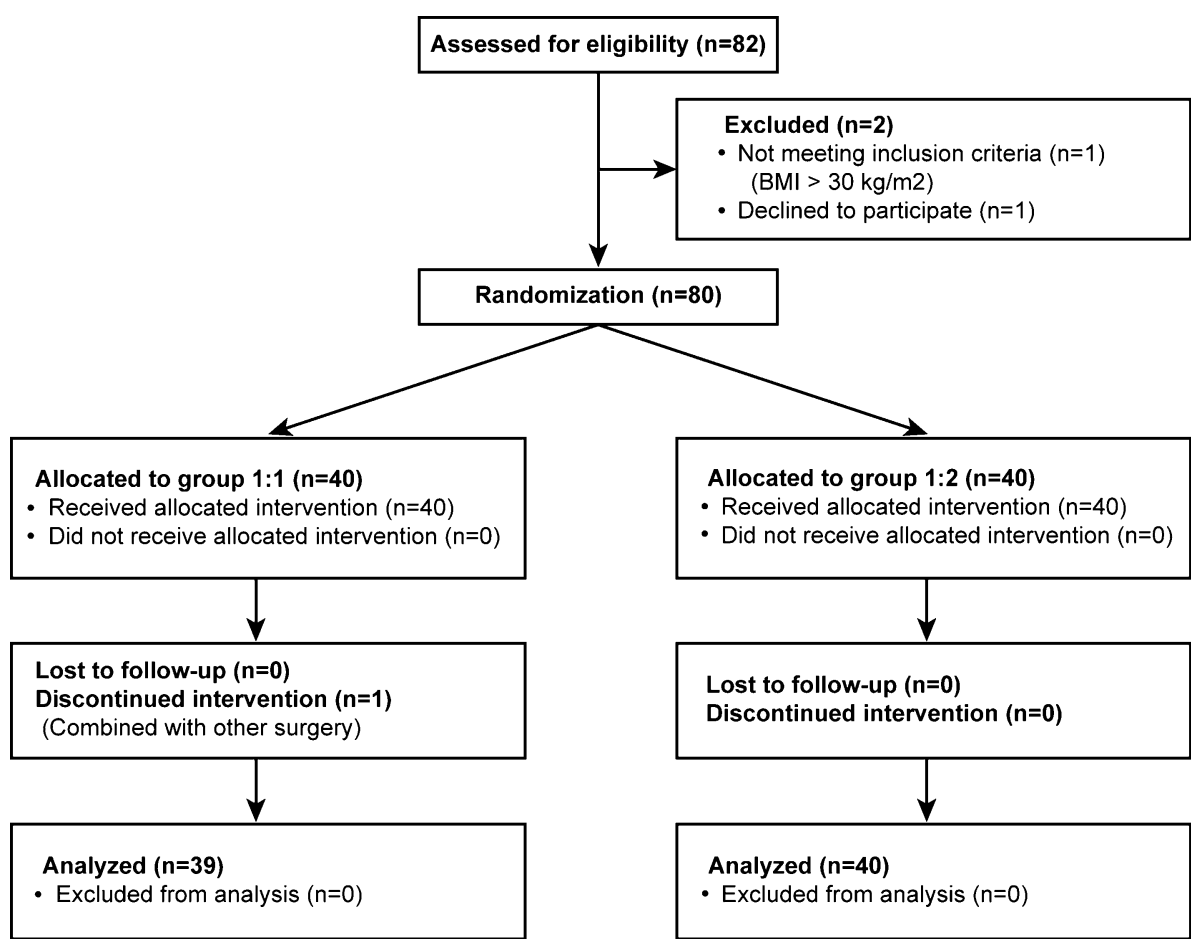


Table 1 Patient characteristics and perioperative data

\begin{tabular}{|c|c|c|}
\hline & Group 1:1 $(n=39)$ & Group 1:2 $(n=40)$ \\
\hline Age $(y r)$ & $65.1(7.2)$ & $64.1(8.5)$ \\
\hline Height $(\mathrm{cm})$ & $169(4)$ & $169(4)$ \\
\hline Weight $(\mathrm{kg})$ & $67.6(8.8)$ & $69.4(8.1)$ \\
\hline Body mass index $\left(\mathrm{kg} \cdot \mathrm{m}^{-2}\right)$ & $23.5(2.7)$ & $24.3(2.4)$ \\
\hline ASA I / II & $13(33 \%) / 26(67 \%)$ & $17(43 \%) / 23(57 \%)$ \\
\hline Hypertension & $20(51 \%)$ & $21(53 \%)$ \\
\hline Diabetes mellitus & $7(18 \%)$ & $4(10 \%)$ \\
\hline Duration of anesthesia (min) & $171(35)$ & $168(33)$ \\
\hline Duration of surgery (min) & $123(32)$ & $121(29)$ \\
\hline Duration of pneumoperitoneum (min) & $92(28)$ & $93(29)$ \\
\hline Total fluid amounts $(\mathrm{mL})$ & $1,533(396)$ & $1,534(413)$ \\
\hline Colloid amounts (mL) & $394(304)$ & $423(287)$ \\
\hline Total urine output $(\mathrm{mL})$ & $264(150)$ & $231(143)$ \\
\hline Total blood loss (mL) & $360(263)$ & $348(220)$ \\
\hline Total ephedrine amounts (mg) & $5.3(7.5)$ & $5.5(6.9)$ \\
\hline Total phenylephrine amounts $(\mu \mathrm{g})$ & $10.3(50.2)$ & 0 \\
\hline PACU duration (min) & $42(17)$ & $40(15)$ \\
\hline Postoperative hospital stay (day) & $3.2(1.7)$ & $2.8(1.2)$ \\
\hline
\end{tabular}

Data are presented as mean (SD) or number of patients (\%)

There were no significant differences between groups

ASA $=$ American Society of Anesthesiologists; PACU = postanesthesia care unit

Table 2 Respiratory data and arterial blood gas analysis

\begin{tabular}{|c|c|c|c|c|c|c|c|c|}
\hline & \multicolumn{2}{|l|}{$\mathrm{T} 1$} & \multicolumn{2}{|l|}{$\mathrm{T} 2$} & \multicolumn{2}{|l|}{ T3 } & \multicolumn{2}{|l|}{$\mathrm{T} 4$} \\
\hline & Group 1:1 & Group 1:2 & Group 1:1 & Group 1:2 & Group 1:1 & Group 1:2 & Group 1:1 & Group 1:2 \\
\hline Ppeak $\left(\mathrm{cm} \mathrm{H}_{2} \mathrm{O}\right)$ & $12.8(2.2)$ & $13.2(1.9)$ & $28.4(4.0)^{*, \dagger}$ & $32.8(5.2)^{\dagger}$ & $27.8(3.9)^{*, \dagger}$ & $32.6(5.0)^{\dagger}$ & $17.1(2.9)^{* \dagger}$ & $18.7(2.6)^{\dagger}$ \\
\hline Pplat $\left(\mathrm{cm} \mathrm{H}_{2} \mathrm{O}\right)$ & $11.9(2.1)$ & $12.9(1.9)$ & $27.7(4.3)^{*, \dagger}$ & $30.9(5.3)^{\dagger}$ & $27.0(3.9)^{*}, \dagger$ & $30.6(5.3)^{\dagger}$ & $15.3(2.6)^{\dagger}$ & $16.7(3.1)^{\dagger}$ \\
\hline Pmean $\left(\mathrm{cm} \mathrm{H}_{2} \mathrm{O}\right)$ & $3.9(1.3)$ & $3.7(1.2)$ & $10.0(1.9)^{*, \dagger}$ & $8.1(1.5)^{\dagger}$ & $10.0(2.0)^{*, \dagger}$ & $8.2(1.6)^{\dagger}$ & $5.3(1.4)^{\dagger}$ & $5.2(1.2)^{\dagger}$ \\
\hline Cstat $\left(\mathrm{mL} \cdot \mathrm{cm} \mathrm{H}_{2} \mathrm{O}\right)$ & $51.3(8.4)$ & $49.2(8.1)$ & $20.2(3.4)^{\dagger}$ & $18.6(3.7)^{\dagger}$ & $20.9(2.9)^{\dagger}$ & $18.9(4.1)^{\dagger}$ & $37.1(5.3)^{\dagger}$ & $36.1(9.2)^{\dagger}$ \\
\hline $\mathrm{RR}$ (breaths. $\min ^{-1}$ ) & $13(9)$ & $12(1)$ & $18(5)^{\dagger}$ & $19(4)^{\dagger}$ & $17(4)^{\dagger}$ & $19(4)^{\dagger}$ & $18(4)^{\dagger}$ & $19(3)^{\dagger}$ \\
\hline $\operatorname{MV}\left(\mathrm{L} \cdot \mathrm{min}^{-1}\right)$ & $6.2(0.9)$ & $6.3(0.9)$ & $9.4(2.5)^{\dagger}$ & $10.1(2.5)^{\dagger}$ & $9.1(2.4)^{\dagger}$ & $10.2(2.4)^{\dagger}$ & $9.3(2.1)^{\dagger}$ & $10.4(2.1)^{\dagger}$ \\
\hline $\mathrm{EtCO}_{2}(\mathrm{mmHg})$ & $32.8(2.2)$ & $32.8(2.5)$ & $39.8(4.1)^{\dagger}$ & $40.8(4.4)^{\dagger}$ & $38.9(3.4)^{\dagger}$ & $40.0(3.8)^{\dagger}$ & $39.3(4.6)^{\dagger}$ & $39.8(4.8)^{\dagger}$ \\
\hline $\mathrm{pH}$ & $7.44(0.03)$ & $7.44(0.03)$ & $7.36(0.04)^{\dagger}$ & $7.35(0.05)^{\dagger}$ & $7.36(0.04)^{\dagger}$ & $7.34(0.04)^{\dagger}$ & $7.37(0.04)^{\dagger}$ & $7.36(0.05)^{\dagger}$ \\
\hline $\mathrm{SaO}_{2}(\mathrm{mmHg})$ & $100(0)$ & $100(0)$ & $100(0)$ & $99(1)$ & $100(1)^{\dagger}$ & $99(1)^{\dagger}$ & $100(1)^{\dagger}$ & $99(1)^{\dagger}$ \\
\hline $\mathrm{PaO}_{2}(\mathrm{mmHg})$ & $205(38)$ & $204(44)$ & $167(32)^{\dagger}$ & $155(35)^{\dagger}$ & $167(36)^{\dagger}$ & $153(35)^{\dagger}$ & $170(30)^{\dagger}$ & $159(34)^{\dagger}$ \\
\hline $\mathrm{PaCO}_{2}(\mathrm{mmHg})$ & $33(3)$ & $32(3)$ & $42(5)^{\dagger}$ & $44(7)^{\dagger}$ & $43(5)^{\dagger}$ & $44(6)^{\dagger}$ & $41(6)^{\dagger}$ & $43(6)^{\dagger}$ \\
\hline Lactate $\left(\mathrm{mmol} \cdot \mathrm{L}^{-1}\right)$ & $1.3(0.5)$ & $1.2(0.5)$ & $1.2(0.4)$ & $1.1(0.4)$ & $1.2(0.5)$ & $1.1(0.5)$ & $1.2(0.4)$ & $1.1(0.5)$ \\
\hline
\end{tabular}

Data are presented as mean (SD)

*The Bonferroni-corrected $P$ value $<0.05$ compared with the counterpart of Group 1:2

${ }^{\dagger}$ Adjusted $P$ value $<0.05$ (using Bonferroni correction) compared with the value of T1 in each group

$\mathrm{T} 1=10 \mathrm{~min}$ after anesthesia induction in the supine position; $\mathrm{T} 2=30 \mathrm{~min}$ after Trendelenburg positioning with $\mathrm{CO}_{2}$ pneumoperitoneum; $\mathrm{T} 3=60 \mathrm{~min}$ after Trendelenburg positioning with $\mathrm{CO}_{2}$ pneumoperitoneum; $\mathrm{T} 4=10 \mathrm{~min}$ after supine positioning without $\mathrm{CO}_{2}$ pneumoperitoneum

Cstat $=$ static compliance $; \mathrm{EtCO}_{2}=$ end-tidal carbon dioxide tension; $\mathrm{MV}=$ minute volume; $\mathrm{PaO}_{2}=$ arterial oxygen tension; $\mathrm{PaCO}_{2}=$ arterial carbon dioxide tension; Pmean = mean airway pressure; Ppeak = peak airway pressure; Pplat = plateau airway pressure; $\mathrm{RR}=$ respiratory rate; $\mathrm{SaO}_{2}=$ arterial oxygen saturation 

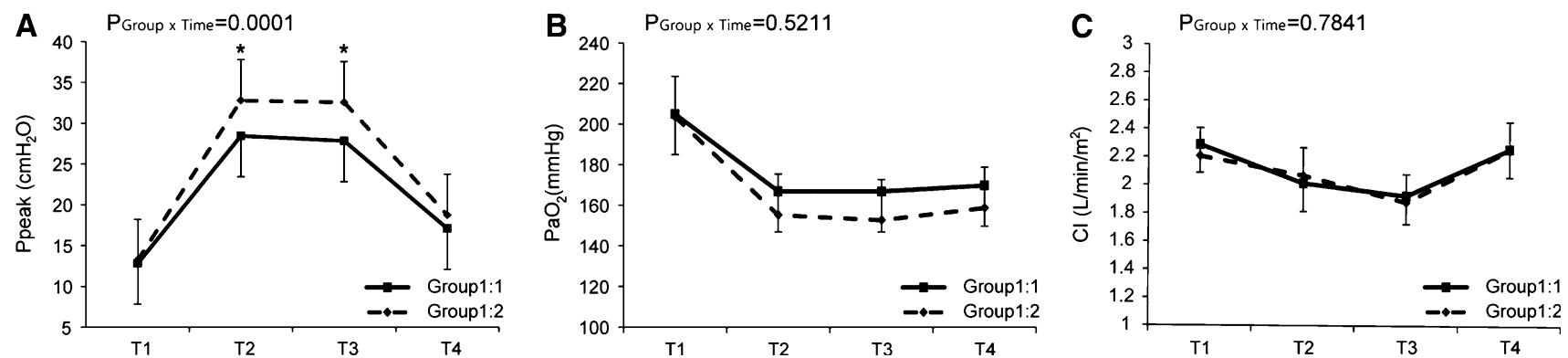

Fig. 2 Change in peak airway pressure (Ppeak) (A), arterial oxygen tension $(\mathrm{PaO} 2)(\mathrm{B})$, and cardiac index $(\mathrm{CI})(\mathrm{C})$ in group 1:1 and $1: 2$ at four times points, from $\mathrm{T} 1$ to $\mathrm{T} 4$, during robot-assisted laparoscopic radical prostatectomy. Linear mixed model analysis showed a significant difference in Ppeak between the two groups $(P<0.001)$. Post hoc analysis with Bonferroni correction showed Ppeak was significantly lower in group 1:1 than in group 1:2 at T2 and T3 (both, $P<0.001$ ), and no significant difference in $\mathrm{PaO} 2$ was detected between the two groups $(P=0.521)$. Cardiac index assessed at each time point was comparable in both groups $(P=0.784)$. Group $1: 1$, I:E ratio of $1: 1$; Group 1:2, I:E ratio of $1: 2$; T1, 10 min after anesthesia induction in the supine position; T2, $30 \mathrm{~min}$ after Trendelenburg positioning with $\mathrm{CO}_{2}$ pneumoperitoneum; T3, $60 \mathrm{~min}$ after Trendelenburg positioning with $\mathrm{CO}_{2}$ pneumoperitoneum; T4, $10 \mathrm{~min}$ after supine positioning without $\mathrm{CO}_{2}$ pneumoperitoneum. * The Bonferroni-corrected $P$ value $<0.05$ compared with the value of group 1:2

Table 3 Hemodynamic data

\begin{tabular}{|c|c|c|c|c|c|c|c|c|}
\hline & \multicolumn{2}{|l|}{$\mathrm{T} 1$} & \multicolumn{2}{|l|}{$\mathrm{T} 2$} & \multicolumn{2}{|l|}{ T3 } & \multicolumn{2}{|l|}{$\mathrm{T} 4$} \\
\hline & Group 1:1 & Group 1:2 & Group 1:1 & Group 1:2 & Group 1:1 & Group 1:2 & Group 1:1 & Group 1:2 \\
\hline HR (beats. $\min ^{-1}$ ) & $68(13)$ & $65(11)$ & $70(12)^{*}$ & $69(10)^{*}$ & $68(12)$ & $68(10)$ & $69(11)$ & $68(12)$ \\
\hline MAP $(\mathrm{mmHg})$ & $75(10)$ & $72(10)$ & $85(10)^{*}$ & $83(10)^{*}$ & $80(8)^{* \dagger}$ & $79(12)^{* \dagger}$ & $76(11)^{\dagger \dagger}$ & $74(12)^{\dagger+}$ \\
\hline $\mathrm{CO}\left(\mathrm{L} \cdot \min ^{-1}\right)$ & $4.1(1.1)$ & $3.9(0.9)$ & $3.6(1.1)$ & $3.7(1.6)$ & $3.4(1.0)$ & $3.4(1.1)$ & $4.0(1.3)^{*}$ & $4.0(1.2)^{*}$ \\
\hline $\mathrm{CI}\left(\mathrm{L} \cdot \mathrm{min}^{-1} \cdot \mathrm{m}^{-2}\right)$ & $2.3(0.5)$ & $2.2(0.6)$ & $2.0(0.6)$ & $2.1(0.9)$ & $1.9(0.6)^{*}$ & $1.9(0.6)^{*}$ & $2.3(0.8)^{*}$ & $2.3(0.7)^{*}$ \\
\hline $\mathrm{SV}\left(\mathrm{mL} \cdot\right.$ beat $\left.^{-1}\right)$ & $57(17)$ & $60(16)$ & $50(17)$ & $55(25)$ & $49(13)^{*}$ & $50(18)^{*}$ & $55(18)^{\ddagger}$ & $59(20)^{\ddagger}$ \\
\hline SVI $\left(\mathrm{mL} \cdot \mathrm{m}^{-2} \cdot\right.$ beat $\left.^{-1}\right)$ & $33(10)$ & $34(9)$ & $29(9)$ & $31(15)$ & $28(7)^{*}$ & $28(11)^{*}$ & $32(12)^{\ddagger}$ & $33(11)^{\ddagger}$ \\
\hline $\operatorname{SVV}(\%)$ & $12.8(3.9)$ & $13.3(3.6)$ & $13.2(4.4)$ & $14.0(4.0)$ & $13.3(4.3)$ & $14.5(3.6)$ & $12.6(4.8)^{*}$ & $12.4(4.0)^{*}$ \\
\hline
\end{tabular}

Data are presented as mean (SD)

*Adjusted $P$ value $<0.05$ (using Bonferroni correction) compared with value of T1 in each group

$\dagger$ Adjusted $P$ value $<0.05$ (using Bonferroni correction) compared with value of $\mathrm{T} 2$ in each group

* Adjusted $P$ value $<0.05$ (using Bonferroni correction) compared with value of T3 in each group

$\mathrm{T} 1=10 \mathrm{~min}$ after anesthesia induction in the supine position; $\mathrm{T} 2=30 \mathrm{~min}$ after Trendelenburg positioning with $\mathrm{CO}_{2}$ pneumoperitoneum; $\mathrm{T} 3=60 \mathrm{~min}$ after Trendelenburg positioning with $\mathrm{CO}_{2}$ pneumoperitoneum; $\mathrm{T} 4=10 \mathrm{~min}$ after supine positioning without $\mathrm{CO}_{2}$ pneumoperitoneum

$\mathrm{CI}=$ cardiac index $; \mathrm{CO}=$ cardiac output $\mathrm{HR}=$ heart rate $\mathrm{MAP}=$ mean arterial pressure; $\mathrm{SV}=$ stroke volume; $\mathrm{SVI}=$ stroke volume index; $\mathrm{SVV}=$ stroke volume variation

two groups (group 1:1 and group 1:2) were similar in patient characteristics and perioperative data (Table 1).

Respiratory data and arterial blood gas analysis are shown in Table 2. For the primary endpoint, the linear mixed model analysis showed a significant difference in Ppeak between the two groups $(P<0.001)$ (Fig. 2A). Post hoc analysis showed a significantly lower mean (SD) Ppeak in group 1:1 than in group 1:2 at T2 [28.4 (4.0) $\mathrm{cm} \mathrm{H}_{2} \mathrm{O} v s$ 32.8 (5.2) $\mathrm{cm} \mathrm{H}_{2} \mathrm{O}$, respectively; mean difference, $4.3 \mathrm{~cm}$ $\mathrm{H}_{2} \mathrm{O} ; 95 \%$ confidence interval $(\mathrm{CI}), 2.3$ to $\left.6.4 ; P<0.001\right]$

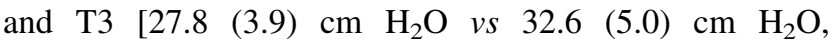
respectively; mean difference, $4.7 \mathrm{~cm} \mathrm{H}_{2} \mathrm{O} ; 95 \% \mathrm{CI}, 2.7$ to 6.7; $P<0.001]$.
Interestingly, Pplat and Pmean showed different patterns between the two groups. During steep Trendelenburg positioning with pneumoperitoneum (T2 and T3), Pplat was significantly lower in group 1:1 than in group 1:2 (T2 mean difference, $3.2 ; 95 \% \mathrm{CI}, 1.0$ to $5.4 ; P=0.018$; and T3 mean difference, $3.6 ; 95 \% \mathrm{CI}, 1.5$ to $5.6 ; P=0.004)$. On the contrary, Pmean was significantly higher in group 1:1 than in group 1:2 (both, $P<0.001$ ).

There was no significant difference in $\mathrm{PaO}_{2}$ between the two groups in the linear mixed model analysis $(P=0.5211)$. The overall hemodynamic parameters (including $\mathrm{CO}$ ) were similar between the two groups (Table 3 and Fig. 2C). Furthermore, no respiratory and 
cardiovascular complications were observed in any of the patients during the intraoperative or postoperative periods.

\section{Discussion}

In this study, an I:E ratio of 1:1 was associated with significantly reduced Ppeak compared with an 1:2 I:E ratio and was without hemodynamic instability during $\mathrm{CO}_{2}$ pneumoperitoneum steep Trendelenburg positioning in robot-assisted laparoscopic radical prostatectomy. Nevertheless, there was no significant difference in $\mathrm{PaO}_{2}$ observed between the groups.

In order to obtain an optimal surgical view, robotassisted laparoscopic radical prostatectomy generally requires the combination of $\mathrm{CO}_{2}$ pneumoperitoneum with steep Trendelenburg positioning, which poses potential problems related to an increased airway pressure and adverse effects on gas exchange. ${ }^{11}$ Increased airway pressure has been associated with serious conditions such as pneumothorax and mediastinal emphysema due to alveolar wall rupture and reduction of right ventricular preload and CO. ${ }^{12-14}$ Carbon dioxide pneumoperitoneum with steep Trendelenburg positioning leads to a cranial displacement of the diaphragm and an increased volume of atelectasis, with a consequent decrease of total lung volume, lung compliance, and functional residual capacity. ${ }^{1,4}$ Thus, alleviation of increased airway pressure and an improvement in oxygenation and $\mathrm{CO}_{2}$ elimination are main goals during anesthetic management in robotassisted laparoscopic radical prostatectomy.

The major mechanism underlying the potential for improved oxygenation by prolonged I:E ratio ventilation is the higher Pmean accompanied by a reduction in Ppeak. ${ }^{5,15}$ In a subject undergoing positive pressure ventilation, Pmean has been considered a primary determinant of oxygenation because it corresponds to mean alveolar pressure, which is the average pressure acting to open and inflate the alveoli against elastic recoil of the lungs. Thus, the elevation of Pmean may improve blood oxygenation due to alveolar recruitment and shunt reduction. ${ }^{15,16}$

Beyond the area of critical care, the use of prolonged I:E ratio ventilation has been considered for general anesthesia under surgical conditions associated with deterioration of gas exchange and respiratory mechanics. In a recent study involving lung surgery, an I:E ratio of 1:1 during one-lung ventilation improved respiratory mechanics, including a decrease in Ppeak and Pplat and an increase in lung compliance. ${ }^{7}$ Nevertheless, additional advantages in terms of overall systemic oxygenation were not observed in this study. Kim et al. also performed the study evaluating the prolonged I:E ratio in laparoscopic gynecologic surgery with steep Trendelenburg positioning. ${ }^{6}$ Their report showed that I:E ratios of 1:1 and 2:1 improved arterial oxygenation with a significant increase in Pmean (SD) compared with an I:E ratio of $1: 2[1: 1=230.3$ (32.3) $\mathrm{mmHg}$ and $2: 1=230.3$ (29.3) $\mathrm{mmHg}$ vs $1: 2=194.3$ (36.8) $\mathrm{mmHg}$, but there were no significant differences in Ppeak and Pplat among the three I:E ratios. ${ }^{6}$

In our study conducted in patients undergoing robotassisted laparoscopic radical prostatectomy, prolongation of inspiratory time lowered Ppeak and Pplat but did not improve their oxygenation. The discrepancy between the results of these two studies, both conducted using $\mathrm{CO}_{2}$ pneumoperitoneum with steep Trendelenburg positioning, might be from differences in the characteristics of the enrolled patients and/or differences in the types of surgery. For example, the previous study by Kim et al. enrolled young female patients, while our present study enrolled elderly male patients with reduced elasticity of lung tissue, a less compliant chest wall, and a lower efficacy of gas exchange. ${ }^{4,9}$ Compared with younger patients, these characteristics of elderly patients could lead to a larger increase in Ppeak and Pplat under similar surgical conditions and result in a significant decrease in Ppeak and Pplat under prolonged inspiratory time. As described above, an I:E ratio of 1:1 also reduced Ppeak and Pplat during one-lung ventilation with compression of the dependent lung. ${ }^{7}$ Thus, the prolonged inspiratory time might be more effective in the improvement of respiratory mechanics in clinical situations with severely reduced lung compliance.

The major concern when using prolonged inspiratory time during positive pressure ventilation is a reduction in CO due to an increase in Pmean., ${ }^{77}$ During one-lung ventilation with an I:E ratio of 1:1, central venous oxygen saturation has been shown to be significantly reduced when compared with an I:E ratio of 1:2.7 Although it could be inferred from this finding that prolonged inspiratory time has a negative effect on $\mathrm{CO}$, the clinical implication or the extent of the reduction in $\mathrm{CO}$ is still unclear. In our study, the measurement of $\mathrm{CO}$ using NICOM was performed during the intraoperative period, and there were no significant differences in $\mathrm{CO}$ between the two I:E ratio groups. Considering the comparable results of the two I:E ratios as regards the other hemodynamic variables and lactate levels, the I:E of 1:1 could be applied to elderly patients under $\mathrm{CO}_{2}$ pneumoperitoneum with steep Trendelenburg positioning without negative effects on hemodynamics.

Instead of volume-controlled ventilation, PCV has been suggested as an alternative mode of ventilation in one-lung surgery and various laparoscopic surgeries, including robotassisted laparoscopic radical prostatectomy and bariatric surgery. ${ }^{11,18-20}$ Unlike volume-controlled ventilation with 
constant flow, PCV with decelerating flow increases mean distribution time, resulting in enhanced oxygenation and reduced Ppeak and Pplat. ${ }^{21}$ In robot-assisted laparoscopic radical prostatectomy, the use of PCV was previously shown to reduce Ppeak with improved lung compliance, although there was no advantage over volume-controlled ventilation regarding oxygenation. ${ }^{11}$ In spite of these advantages regarding respiratory mechanics, a limitation to the application of PCV could be the variability in tidal volume delivered to patients according to the change in lung compliance. ${ }^{7}$ From the results of our study using volumecontrolled ventilation, mean (SD) Ppeak with an I:E ratio of 1:1 was lower or similar to that observed in the previous report using PCV when performing a robot-assisted laparoscopic radical prostatectomy [27.8 (3.9) $\mathrm{cm} \mathrm{H}_{2} \mathrm{O} v s 29.2$ (5.0) $\mathrm{cm}$ $\mathrm{H}_{2} \mathrm{O}$, respectively]. ${ }^{11}$ When considering the advantage of ensuring tidal volume, volume-controlled ventilation using prolonged inspiratory time could be a better option than PCV in robot-assisted laparoscopic radical prostatectomy.

Our study has some limitations to be considered when interpreting our results. First, the reliability of the noninvasive $\mathrm{CO}$ monitoring using NICOM has been a conflicting issue, and its further validation is still ongoing. ${ }^{22-24}$ Considering the hemodynamic effects of the prolonged inspiratory time, its safety should be confirmed by CO measurement, especially in elderly patients undergoing robot-assisted laparoscopic radical prostatectomy. Cardiac output monitoring with a thermodilution technique using a pulmonary artery catheter has become the most common approach and has been considered as the reference used to validate noninvasive techniques. ${ }^{25}$ Nevertheless, this invasive method involves risks of serious complications such as dysrhythmias, pneumothorax, perforation of the cardiac chamber, and rupture of the pulmonary artery. ${ }^{26}$ All noninvasive $\mathrm{CO}$ monitoring techniques confer a safety advantage inherent in their noninvasiveness; they also have their own potential disadvantages. ${ }^{23,25}$ In the current study, the presence of arterial pressure monitoring in these patients would have allowed estimation of $\mathrm{CO}$ using the FloTrac ${ }^{\mathrm{TM}}$ system; however, we chose to use NICOM as it was more accessible than the FloTrac at our institution and it has completely noninvasive characteristics. Second, from our results, the I:E ratio of 1:1 did not improve oxygenation, so its clinical implications might be somewhat weak. Nevertheless, in volume-controlled ventilation with an I:E ratio of 1:1, the significant reduction of Ppeak and Pplat was observed in the same manner as results from the previous study using PCV in robot-assisted laparoscopic radical prostatectomy, and the prolonged inspiratory time and an accompanied increase of Pmean were not associated with reduced $\mathrm{CO}$. In addition, previous studies have reported that $\mathrm{CO}_{2}$ pneumoperitoneum with steep Trendelenburg positioning could result in an increase in intracranial pressure (ICP). ${ }^{2,27}$ Hence, maintaining normocapnia is recommended in order to minimize the resultant elevation of ICP, and the reduced Ppeak and Pplat at an I:E ratio of 1:1 could be beneficial to ensure an sufficient minute volume. ${ }^{4}$ Third, overall differences in the arterial to end-tidal $\mathrm{CO}_{2}$ levels were smaller than those reported in previous studies. ${ }^{28,29}$ This discrepancy between the results could be attributed to the differences in the time gap between blood sampling and analysis, patient characteristics, ventilator settings, and the tilting angle. Lastly, our study did not enrol patients with respiratory diseases or obesity $\left(\mathrm{BMI}>30 \mathrm{~kg} \cdot \mathrm{m}^{-2}\right)$, as these patients could be more vulnerable to deterioration of oxygenation and respiratory mechanics during $\mathrm{CO}_{2}$ pneumoperitoneum with steep Trendelenburg positioning. Further studies are needed in order to validate the safety and efficacy of prolonged I:E ratio in these patients.

In conclusion, volume-controlled ventilation with an I:E ratio of $1: 1$ could be a feasible alternative method to lower Ppeak without hemodynamic instability during $\mathrm{CO}_{2}$ pneumoperitoneum with steep Trendelenburg positioning. Nevertheless, our results did not support its use for improving oxygenation.

Acknowledgements The authors thank the biostatisticians of the Department of Research Affairs for their statistical comments and analysis as well as Dong-Su Jang, MFA, medical illustrator, Medical Research Support Section, Yonsei University College of Medicine, for his help with the figures.

Funding Funding was provided solely from departmental sources.

Conflict of interest None of the authors have identified a conflict of interest.

\section{References}

1. Andersson LE, Baath M, Thorne A, Aspelin P, OdebergWernerman $S$. Effect of carbon dioxide pneumoperitoneum on development of atelectasis during anesthesia, examined by spiral computed tomography. Anesthesiology 2005; 102: 293-9.

2. Kim MS, Bai SJ, Lee JR, Choi YD, Kim YJ, Choi SH. Increase in intracranial pressure during carbon dioxide pneumoperitoneum with steep Trendelenburg positioning proven by ultrasonographic measurement of optic nerve sheath diameter. J Endourol 2014; 28: 801-6.

3. Wilcox S, Vandam LD. Alas, poor Trendelenburg and his position! A critique of its uses and effectiveness. Anesth Analg 1988; 67: 574-8.

4. Gainsburg DM. Anesthetic concerns for robotic-assisted laparoscopic radical prostatectomy. Minerva Anestesiol 2012; 78: 596-604.

5. Zavala E, Ferrer $M$, Polese $G$, et al. Effect of inverse I: E ratio ventilation on pulmonary gas exchange in acute respiratory distress syndrome. Anesthesiology 1998; 88: 35-42.

6. Kim WH, Hahm TS, Kim JA, et al. Prolonged inspiratory time produces better gas exchange in patients undergoing laparoscopic surgery: a randomised trial. Acta Anaesthesiol Scand 2013; 57 : 613-22. 
7. Kim SH, Choi YS, Lee JG, Park IH, Oh YJ. Effects of a 1:1 inspiratory to expiratory ratio on respiratory mechanics and oxygenation during one-lung ventilation in the lateral decubitus position. Anaesth Intensive Care 2012; 40: 1016-22.

8. Sinha M, Chiplonkar S, Ghanshani R. Pressure-controlled inverse ratio ventilation using laryngeal mask airway in gynecological laparoscopy. J Anaesthesiol Clin Pharmacol 2012; 28: 330-3.

9. Deiner $S$, Silverstein JH. Anesthesia for geriatric patients. Minerva Anestesiol 2011; 77: 180-9.

10. Merchant $R$, Chartrand D, Dain $S$, et al. Guidelines to the practice of anesthesia - revised edition 2015. Can J Anesth 2015; 62: 54-79.

11. Choi EM, Na S, Choi SH, An J, Rha KH, Oh YJ. Comparison of volume-controlled and pressure-controlled ventilation in steep Trendelenburg position for robot-assisted laparoscopic radical prostatectomy. J Clin Anesth 2011; 23: 183-8.

12. Shekerdemian L, Bohn D. Cardiovascular effects of mechanical ventilation. Arch Dis Child 1999; 80: 475-80.

13. Marcy TW. Barotrauma: detection, recognition, and management. Chest 1993; 104: 578-84.

14. Gammon RB, Shin MS, Buchalter SE. Pulmonary barotrauma in mechanical ventilation. Patterns and risk factors. Chest 1992; 102: 568-72.

15. Marcy $T W$, Marini JJ. Inverse ratio ventilation in ARDS. Rationale and implementation. Chest 1991; 100: 494-504.

16. Herman S, Reynolds EO. Methods for improving oxygenation in infants mechanically ventilated for severe hyaline membrane disease. Arch Dis Child 1973; 48: 612-7.

17. Mercat A, Graini L, Teboul JL, Lenique F, Richard C. Cardiorespiratory effects of pressure-controlled ventilation with and without inverse ratio in the adult respiratory distress syndrome. Chest 1993; 104: 871-5.

18. Cadi P, Guenoun T, Journois D, Chevallier JM, Diehl JL, Safran $D$. Pressure-controlled ventilation improves oxygenation during laparoscopic obesity surgery compared with volume-controlled ventilation. Br J Anaesth 2008; 100: 709-16.

19. Ogurlu $M$, Kucuk $M$, Bilgin F, et al. Pressure-controlled vs volume-controlled ventilation during laparoscopic gynecologic surgery. J Minim Invasive Gynecol 2010; 17: 295-300.
20. Tugrul M, Camci E, Karadeniz H, Senturk M, Pembeci K, Akpir $K$. Comparison of volume controlled with pressure controlled ventilation during one-lung anaesthesia. Br J Anaesth 1997; 79: 306-10.

21. Prella M, Feihl F, Domenighetti G. Effects of short-term pressure-controlled ventilation on gas exchange, airway pressures, and gas distribution in patients with acute lung injury/ARDS: comparison with volume-controlled ventilation. Chest 2002; 122: 1382-8.

22. Kupersztych-Hagege E, Teboul JL, Artigas A, et al. Bioreactance is not reliable for estimating cardiac output and the effects of passive leg raising in critically ill patients. Br J Anaesth 2013; 111: 961-6.

23. Waldron NH, Miller TE, Thacker JK, et al. A prospective comparison of a noninvasive cardiac output monitor versus esophageal Doppler monitor for goal-directed fluid therapy in colorectal surgery patients. Anesth Analg 2014; 118: 966-75.

24. Squara P, Denjean D, Estagnasie P, Brusset A, Dib JC, Dubois $C$. Noninvasive cardiac output monitoring (NICOM): a clinical validation. Intensive Care Med 2007; 33: 1191-4.

25. Marik PE. Noninvasive cardiac output monitors: a state-of the-art review. J Cardiothorac Vasc Anesth 2013; 27: 121-34.

26. Hadian M, Pinsky MR. Evidence-based review of the use of the pulmonary artery catheter: impact data and complications. Crit Care 2006; 10(Suppl 3): S8.

27. Josephs LG, Este-McDonald JR, Birkett DH, Hirsch EF . Diagnostic laparoscopy increases intracranial pressure. J Trauma 1994; 36: 815-8; discussion 818-9.

28. Lestar M, Gunnarsson L, Lagerstrand L, Wiklund P, OdebergWernerman $S$. Hemodynamic perturbations during robot-assisted laparoscopic radical prostatectomy in $45^{\circ}$ Trendelenburg position. Anesth Analg 2011; 113: 1069-75.

29. Kalmar AF, Foubert L, Hendrickx JF, et al. Influence of steep Trendelenburg position and $\mathrm{CO}(2)$ pneumoperitoneum on cardiovascular, cerebrovascular, and respiratory homeostasis during robotic prostatectomy. Br J Anaesth 2010; 104: 433-9. 